\title{
Contralateral hearing loss as an effect of venous congestion at the ipsilateral inferior colliculus after microvascular decompression: report of a case
}

\author{
Christian Strauss, Ramin Naraghi, Barbara Bischoff, Walter J Huk, Johann Romstöck
}

\begin{abstract}
Contralateral hearing loss after surgical procedures within the cerebellopontine angle is rarely seen and its pathophysiological background is not yet understood. A patient with contralateral hearing loss after microvascular decompression for trigeminal neuralgia is described. Ipsilateral brainstem auditory potential (BAEP) monitoring and facial nerve EMG did not show major abnormalities. During otherwise uneventful and successful surgery a branch of the petrosal vein was sacrificed to widen the access to the trigeminal root exit zone. On the third postoperative day the patient complained about contralateral hearing loss, which was verified by audiometry. Contralateral BAEPs showed low amplitudes and delayed interpeak latencies. Brain CT was normal. Brain MRI on the 8 th postoperative day disclosed abnormal signals within the ipsilateral inferior colliculus. Intravenous heparinisation was performed and hearing slowly recovered over a 3 month period. Results from this patient offer a pathophysiological mechanism for contralateral hearing loss after cerebellopontine angle surgery, illustrate the importance of venous drainage preservation, gives evidence about the generation of BAEP components within the contralateral brainstem, and stresses the importance of intraoperative BAEP monitoring.

(F Neurol Neurosurg Psychiatry 2000;69:679-682)
\end{abstract}

Keywords: auditory pathways; cerebellopontine angle surgery; contralateral hearing loss; microvascular decompression; superior petrosal vein

Contralateral hearing loss after surgical procedures within the cerebellopontine angle is rarely found. ${ }^{1-9}$ Pathophysiological considerations include brainstem shift and oedema after removal of large tumours, intracochlear fluid dysfunction caused by CSF release, and immunological reactions due to labyrinthine injury. $^{2} 3578$ 10-12
Case report

A 52 year old woman was admitted for microvascular decompression in typical V3 trigeminal neuralgia on the right side. A preoperative audiogram showed bilateral normal hearing. Brain MRI showed an arterial loop of the superior cerebellar artery with compression of the trigeminal nerve root exit zone and normal brain stem anatomy at the pontomesencephalic junction (fig 1). Microvascular decompression was uneventful except for dissection of the pontotrigeminal vein, proximal to the superior petrosal vein complex. Intraoperative ipsilateral BAEPs showed no abnormalities, except for a minor temporary latency shift of wave $V .^{13}$ The use of insert earphones with a $20 \mathrm{~cm}$ silicone tube extension resulted in a peak delay of 0.60 ms, compared with conventional headphones. After surgery the neuralgia resolved completely, but on the third postoperative day the patient complained of contralateral hearing loss. Audiometry showed a profound contralateral pancochlear hearing loss with a pure tone average (PTA), calculated at 500, 1000, 2000, and $3000 \mathrm{~Hz}$ of $69 \mathrm{~dB}$ predominantly in the lower frequency range and normal hearing on the operated side (fig 2). Cranial CT was normal. Contralateral BAEP obtained with insert earphones and a stimulation intensity of $95 \mathrm{~dB}$ normal hearing level showed low amplitudes throughout peaks I to V, loss of components, and a discrete delayed interpeak latency III-V of $2.16 \mathrm{~ms}$ compared with $1.81 \mathrm{~ms}$ (laboratory control group, table). No major abnormalities were seen on ipsilateral BAEP (fig 3, table). Intravenous medical treatment consisting of hydroxyethylstarch, lidocaine, prednisolone, and pentoxifyllin was given according to a treatment protocol for a total of 10 days. Control audiometry, performed on the 8th postoperative day, showed further deterioration with a PTA of $78 \mathrm{~dB}$ (fig 2). Brain MRI on the same day showed a hyperintense signal below the level of the inferior ipsilateral inferior colliculus consistent with venous congestion (fig 1). The patient was started on intravenous heparin (25 $000 \mathrm{IU} / 24 \mathrm{~h}$ ) for 11 days and hearing showed slight improvement during the subsequent days (fig 2). Three months after surgery BAEP latencies and amplitudes had improved, hearing had further improved with a PTA of $65 \mathrm{~dB}$ 

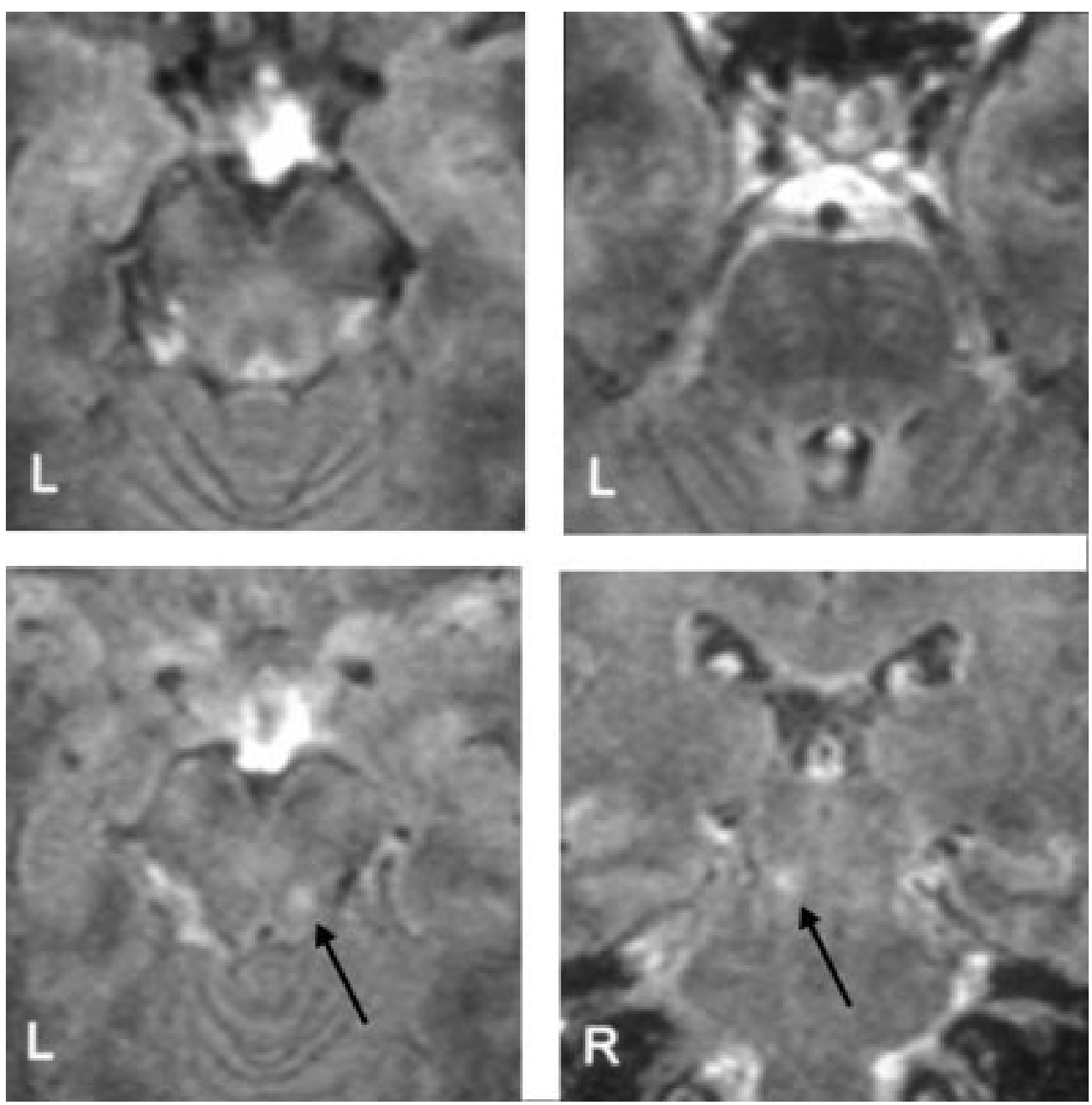

Figure 1 Preoperative MRI flair sequences showing normal anatomical structures of the pontomesencephalic junction (upper). Postoperative MRI flair sequences disclosing a hyperintense lesion below the level of the ipsilateral inferior colliculus (lower).

and recovery of speech discrimination (fig 2). Brain MRI showed partial resolution of the lesion.

\section{Discussion}

Profound contralateral hearing loss after cerebellopontine surgery can be a devastating complication for a patient, particularly in surgery for acoustic neurinoma. ${ }^{2358}$ Fortunately, Its incidence is very low. Barker and
Jannetta reported one contralateral hearing loss in 1185 cases of microvascular decompression for trigeminal neuralgia. ${ }^{1}$ In surgery for acoustic neurinoma its incidence was found to be $1.3 \%$, considering a loss of more than $20 \mathrm{~dB}$ as significant. ${ }^{9}$ Its pathophysiological mechanism is not yet fully understood. Brainstem shift, brainstem oedema, labyrinthine fluid imbalance due to CSF release and even a contralateral sympathetic labyrinthitis due to

\section{July 1999 Postop 18 October 1999 Postop}

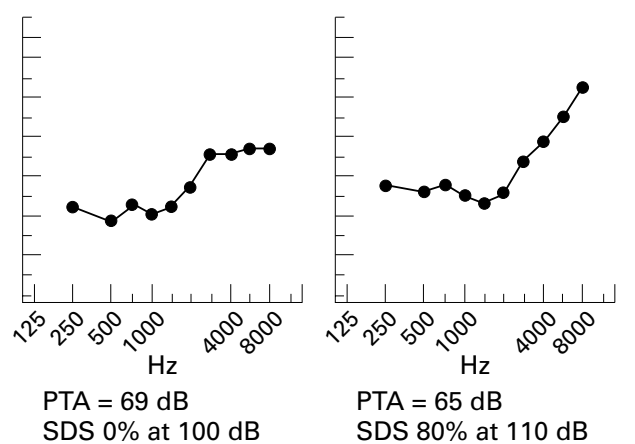

Figure 2 Preoperative and postoperative serial pure tone audiograms of the contralateral ear. Normal hearing is documented before surgery (left). Profound hearing loss with complete loss of speech discrimination is demonstrated on the 4th postoperative day (12 fuly 1999), which gradually worsened despite vasoactive therapy (16 fuly 1999), and recovered after heparinisation. An audiogram 3 months after surgery documents further recovery (right). 
Stimulation: left ear

$\mathrm{L}$

$\mathrm{R}$

8 July 1999

- Not recorded -

14 July 1999
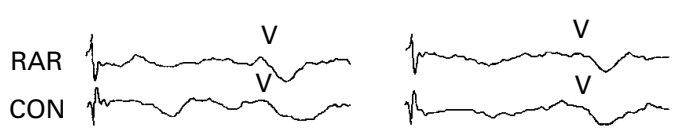

30 July 1999
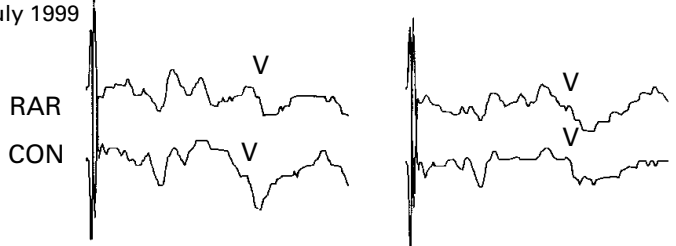

18 October 1999
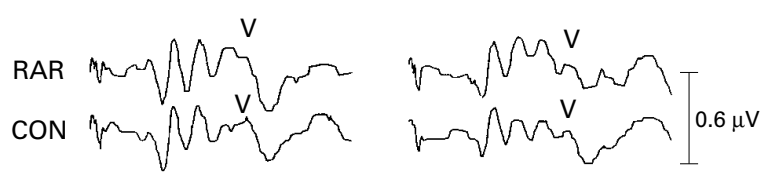

$$
\longmapsto 11 \mathrm{~ms}
$$

Stimulation: right ear

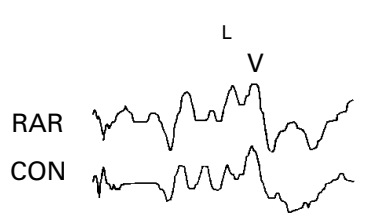

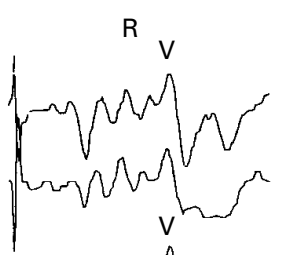

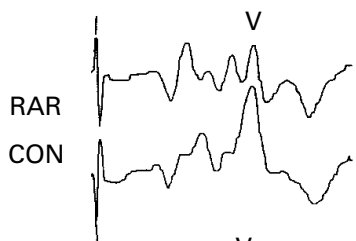

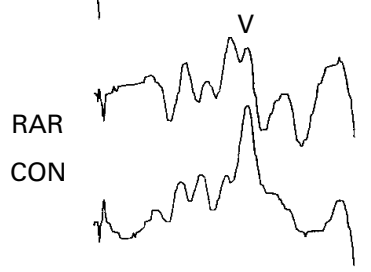

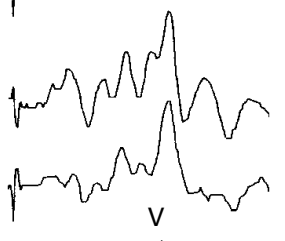

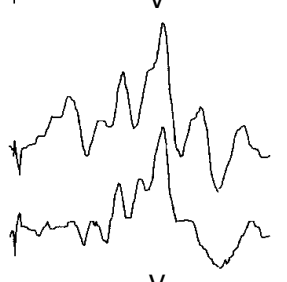

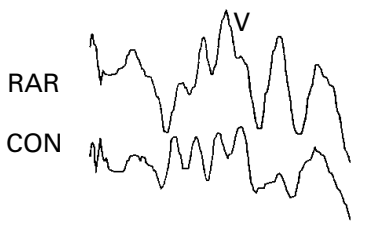

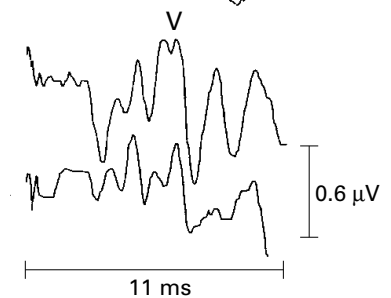

Figure 3 Preoperative and postoperative serial BAEPs after contralateral (left side) and ipsilateral (right side) stimulation shows normal BAEPs at the side of surgery and massively distorted potentials after contralateral stimulation. Potentials slowly recovered over a 3 month period.

injury of the ipsilateral labyrinth after translabyrinthine resection of acoustic neurinomas have been discussed as possible causes. $^{2} 3578$ 10-12 The presented case with intraoperative dissection of the pontotrigeminal vein, which receives drainage from the lateral mesencephalic vein, the late onset of symptoms on the 3rd postoperative day, the postoperative MRI showing abnormal signals below the level of the ipsilateral inferior colliculus, and the clinical recovery after heparinisation clearly point to the venous drainage system of the superior petrosal vein as the most likely cause for contralateral hearing loss. The venous drainage system of the superior petrosal vein has received little attention in the surgical management of cerebellopontine lesions. ${ }^{14-16}$ Due to its variabil-

Ipsilateral and contralateral latencies and amplitudes of serial BAEP recordings.

\begin{tabular}{|c|c|c|c|c|c|c|c|c|c|c|c|c|c|c|}
\hline & \multicolumn{7}{|c|}{ Recording left ear } & \multicolumn{7}{|c|}{ Recording right ear } \\
\hline & \multicolumn{4}{|c|}{ Latencies (ms) } & \multicolumn{3}{|c|}{ Amplitudes $(\mu V)$} & \multicolumn{4}{|c|}{ Latencies (ms) } & \multicolumn{3}{|c|}{ Amplitudes $(\mu V)$} \\
\hline & $I$ & III & $V$ & $I I I-V$ & $I$ & $I I I$ & $V$ & $I$ & $I I I$ & $V$ & $I I I-V$ & $I$ & III & $V$ \\
\hline \multicolumn{15}{|c|}{ Stimulation right ear } \\
\hline RAR & & 4.83 & 6.62 & 1.79 & & 0.09 & 0.46 & 2.28 & 4.79 & 6.56 & 1.77 & 0.06 & 0.22 & 0.63 \\
\hline $\mathrm{CON}$ & & 4.60 & 6.55 & 1.95 & & 0.18 & 0.36 & 2.50 & 4.59 & 6.42 & 1.83 & 0.45 & 0.24 & 0.44 \\
\hline \multicolumn{15}{|c|}{14 July $1999:$} \\
\hline RAR & & 4.47 & 6.59 & 1.82 & & 0.16 & 0.39 & 2.37 & 4.83 & 6.60 & 1.77 & 0.39 & 0.33 & 0.76 \\
\hline $\mathrm{CON}$ & & 4.52 & 6.57 & 2.05 & & 0.29 & 0.58 & 2.06 & 4.62 & 6.54 & 1.92 & 0.21 & 0.17 & 0.63 \\
\hline \multicolumn{15}{|c|}{30 July 1999 : } \\
\hline RAR & & 4.62 & 6.27 & 1.65 & & 0.13 & 0.56 & 2.37 & 4.67 & 6.27 & 1.60 & 0.43 & 0.38 & 0.90 \\
\hline $\mathrm{CON}$ & & 4.37 & 6.27 & 1.90 & & 0.26 & 0.61 & 2.37 & 4.46 & 6.26 & 1.80 & 0.16 & 0.23 & 0.66 \\
\hline \multicolumn{15}{|c|}{18 October $1999:$} \\
\hline RAR & & 4.61 & 6.32 & 1.71 & & 0.26 & 0.46 & 2.36 & 4.53 & 6.14 & 1.61 & 0.55 & 0.42 & 0.99 \\
\hline $\mathrm{CON}$ & & 4.31 & 6.15 & 1.84 & & 0.33 & 0.46 & 2.46 & 4.37 & 6.12 & 1.75 & 0.18 & 0.48 & 0.58 \\
\hline \multicolumn{15}{|c|}{ Stimulation left ear } \\
\hline $\begin{array}{l}\text { RAR } \\
\text { CON }\end{array}$ & & & - & & & - & & & & - & & & - & \\
\hline \multicolumn{15}{|c|}{ 14 July 1999: } \\
\hline RAR & 2.10 & 5.13 & 7.05 & 1.92 & 0.10 & 0.02 & 0.15 & & 4.82 & 6.98 & 2.18 & & & 0.16 \\
\hline $\mathrm{CON}$ & 2.06 & 4.91 & 7.05 & 2.16 & 0.12 & 0.09 & 0.17 & & 4.82 & 6.77 & 1.95 & & & 0.16 \\
\hline \multicolumn{15}{|c|}{30 July 1999: } \\
\hline RAR & 2.36 & 4.67 & 6.68 & 2.01 & 0.16 & 0.21 & 0.22 & & 4.67 & 6.63 & 1.96 & & 0.11 & 0.14 \\
\hline $\mathrm{CON}$ & 2.40 & 4.85 & 6.40 & 1.74 & 0.23 & & 0.24 & & 4.49 & 6.48 & 1.99 & & 0.05 & 0.18 \\
\hline \multicolumn{15}{|c|}{18 October $1999:$} \\
\hline RAR & 2.39 & 4.43 & 6.29 & 1.86 & 0.29 & 0.23 & 0.37 & & 4.41 & 6.44 & 2.03 & & 0.10 & 0.17 \\
\hline $\mathrm{CON}$ & 2.37 & 4.32 & 6.36 & 2.04 & 0.28 & 0.27 & 0.31 & & 4.35 & 6.30 & 1.95 & & 0.17 & 0.22 \\
\hline
\end{tabular}


ity and the richness of collaterals it is difficult to attribute morbidity specifically to the venous system. Matsushima et al in 1989 investigated the superior petrosal vein complex and identified three different groups (medial, intermediate, lateral) with one to three singular veins, the medialmost tributary of which can be sacrified..$^{15}$ McLauglin et al routinely divide the superior petrosal vein complex during microvascular decompression for trigeminal neuralgia without adverse effects. ${ }^{6}$

Preservation of the superior petrosal vein during cerebellopontine angle surgery is usually not specifically considered, ${ }^{17}$ although its potential danger has been described several times. ${ }^{18-20}$ Sweet and Poletti, in their retrospective analysis of microvascular decompression procedures, performed in 49 different neurosurgical services, attributed four complications to "coagulation of essential veins draining the brainstem" ${ }^{19}$ In cases with presumably normal anatomy, thrombosis or injury of the superior petrosal sinus is reported to cause significant brainstem morbidity, as in a recently published case of Raymond's syndrome after superior petrosal sinus sampling for diagnostic investigation in Cushing's syndrome, ${ }^{21}$ and in a case of microvascular decompression with transient peduncular hallucinosis after dissection of the superior petrosal vein complex. ${ }^{20}$

Dissection of the pontotrigeminal vein, which receives drainage from the lateroposterior aspect of the mesencephalon including the colliculi via the lateral mesencephalic vein can certainly be the cause for contralateral hearing loss in the reported case. The variability of venous drainage patterns to the pons and medulla ${ }^{15}$ cautions against drawing conclusions from a singular case; however, the sacrifice of draining veins can be associated with cranial nerve dysfunction. Intraoperative BAEP monitoring during surgical procedures within the cerebellopontine angle is usually limited to the ipsilateral side. Venous congestion would most likely not have been seen by contralateral stimulation, especially as the clinical manifestation of contralateral hearing loss did not occur until the 3 rd postoperative day.

This case further enhances the ongoing discussion about the generation of waves ipsilaterally or contralaterally. ${ }^{22}$ The profound contralateral hearing loss, the MRI documentation of an ipsilateral brainstem lesion below the level of the inferior colliculus, and the distorted low amplitude waveforms after contralateral stimulation with surprisingly little III-V IPL shift, give evidence for a significant contribution of crossed pathways to BAEPs. As the cochlear pathway crosses at the level of the corpus trapezoideum to the contralateral side, contralat- eral peak $\mathrm{V}$ analysis should be included in the protocol for ipsilateral monitoring of cochlear nerve function. This is particularly important in acoustic neurinoma surgery with distorted potentials, in which often ipsilateral peaks beyond wave I become poorly distinguishable during tumour removal.

1 Barker FG, Jannetta PJ, Bissonette DJ, et al. Long term outcome after microvascular decompression for typical trigeminal neuralgia. N Engl f Med 1996:334:1077-83.

2 Clemis JD, Mastricola PG, Schuler-Vogler M. Sudden hearing loss in the contralateral ear in postoperative acoustic tumor: three case reports. Laryngoscope 1982;92:76-9.

3 Chovanes GI, Buchheit WA. Bilateral hearing loss after unilateral removal of an acoustic neuroma by the suboccipital approach: case report. Neurosurgery 1986;19:452-3.

4 De Keyser J, Bruyland M, Demol P, et al. Sudden hearing loss and facial palsy at the contralateral side following acoustic tumor removal. F Neurol Neurosurg Psychiatry 1983;46:687.

5 Harada K, Komatsuzaki A, Takahashi H, et al. Acute hearing loss in the contralateral ear after acoustic tumor

Mc Laughlin MR, Jannetta PJ. Clyde BL, et al. Microvascular decompression of cranial nerves: lessons learned after 4400 operations. $\mathcal{F}$ Neurosurg 1999;90:1-8.

7 Nishioka T, Ishikawa M, Kondo A, et al. Contralateral deafness following unilateral suboccipital brain tumor surgery in a patient with large vestibular aqueduct - case report. Neurol Med Chir (Tokyo) 1998;38:871-4.

8 Walsh RM, Murrty JA, O'Donoghue GM. Sudden contralateral deafness following cerebellopontine angle tumor surgery. Am f Otol 1994;15:244-6.

9 Harris JP, Low NC, House WF. Contralateral hearing loss following inner ear injury: sympathetic cochleolabyrinthitis? Am $\mathcal{F}$ Otol 1985;6:371-7.

10 Barratt HJ, Prasher DK. The effect of acoustic neuroma removal on hearing in the contralateral ear. Scand Audiol 1988;17:137-42.

11 Magliulo G, Ronzoni R, Vingolo GM, et al. The contralateral ear after surgery in different otoneurosurgical or neurosurgical pathologies. Acta Otorhinolaryngol Belg or neurosurgical

12 Walsted A, Salomon G, Thomsen J, et al. Cerebrospinal fluid loss and threshold changes. 1. Hearing loss in the contralateral ear after operation for acoustic neuroma: an analysis of the incidence, time course frequency range, size and pathophysiological considerations. Audiol Neurootol 1996;1:247-55

13 Neu M, Strauss C, Romstöck J, et al. The prognostic value of intraoperative BAEP patterns in acoustic neurinoma surgery. Clin Neurophysiol 1999;110:1935-41.

14 Matsushima T, Rhoton AL Jr, de Oliveira E, et al. Microsurgical anatomy of the veins of the posterior fossa. 7 Neurosurg 1983;59:63-105.

15 Matsushima T, Fukui M, Suzuki S, et al. The microsurgical anatomy of the infratentorial lateral supracerebellar approach to the trigeminal nerve for tic douloureux. proach to the trigeminal
Neurosurgery $1989 ; 24: 890-5$.

16 Rhoton AL jr. Microsurgical anatomy of acoustic neuromas. Rhoton AL jr. Microsurgical
Neurol Res 1984;6:3-21.

17 Samii M, Matthies C. Management of 1000 vestibular schwannomas (acoustic tumors): surgical management and results with emphasis on complications and how to avoid them. Neurosurgery 1997;40:11-23.

18 Fujimaki T, Kirino T. Coagulation of the petrosal vein for MVD. Letter to the editor. F Neurosurg 1999;90:1148.

19 Sweet WH, Poletti CE. Complications of percutaneous rhizotomy and microvascular decompression for facial pain. In: Schmidek $\mathrm{HH}$, Sweet WH, eds. Operative neurosurgical techniques, ed 3. Philadelphia: WB Saunders, 1995:1543-6.

20 Tsukamoto H, Matsushima T, Fujiwara S, et al. Peduncular hallucinosis following microvascular decompression for trigeminal neuralgia. Case report. Surg Neurol 1993;40:31trige

21 Seyer H, Honegger J, Schott W, et al. Raymond's syndrome following petrosal sinus sampling. Acta Neurochir (Wien) 1994;131:157-9.

22 Moller AR, Jho HD, Yokota M, et al. Contribution from crossed and uncrossed brainstem structures to the brainstem auditory evoked potentials: a study in humans. Laryngoscope 1995;105:596-605. 